\title{
Tricuspid valve replacement in failing Fontan circulation with severe ventricular dysfunction: The road not taken?
}

\author{
and Igor E. Konstantinov, MD, PhD, FRACS, ${ }^{\text {a,b,c,d }}$ Melbourne, Australia \\ From the ${ }^{\mathrm{a}}$ Department of Cardiac Surgery and ${ }^{\mathrm{b}}$ Department of Cardiology, The Royal Children's Hospital, Mel- \\ bourne, Victoria, Australia; 'Department of Pediatrics, University of Melbourne, Melbourne, Victoria, \\ Australia; and ${ }^{\mathrm{d}}$ Murdoch Children's Research Institute, Heart Research group, Melbourne, Victoria, Australia \\ Disclosures: Authors have nothing to disclose with regard to commercial support. \\ Received for publication Dec 20, 2017; revisions received Feb 26, 2018; accepted for publication March 18, 2018 ; \\ available ahead of print April 27, 2018 \\ Address for reprints: Igor E. Konstantinov, MD, PhD, FRACS, Department of Cardiac Surgery, The Royal Chil- \\ dren's Hospital, 50 Flemington Rd, Parkville, Victoria 3052, Australia (E-mail: igor.konstantinov@ rch.org.au). \\ J Thorac Cardiovasc Surg 2018; 156:e141-3 \\ $0022-5223 / \$ 36.00$ \\ Copyright $(2018$ by The American Association for Thoracic Surgery \\ https://doi.org/10.1016/j.jtcvs.2018.03.097
}

Stephanie L. Perrier, MD, ${ }^{\mathrm{a}}$ Michael Z. L. Zhu, MBBS, BMedSc, ${ }^{a}$ Robert G. Weintraub, MBBS, FRACP, ${ }^{\mathrm{b}, \mathrm{c}, \mathrm{d}}$
Video clip is available online.

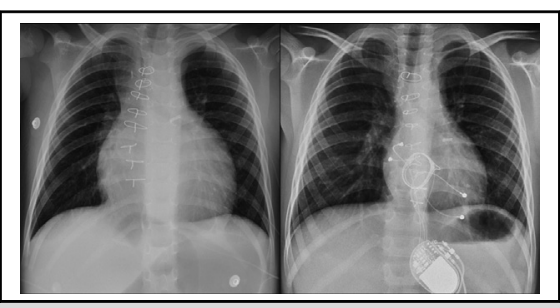

Reduction of cardiothoracic ratio after TV replacement in a patient with palliated HLHS.

Central Message

Tricuspid valve replacement in a patient with Fontan failure caused by severe right ventricular dilatation and tricuspid valve insufficiency may result in resolution of heart failure.

See Editorial Commentary page e 145.
In patients with hypoplastic left heart syndrome (HLHS) and right ventricular (RV) dilatation and failure, tricuspid valve (TV) replacement is rarely performed after Fontan completion. ${ }^{1}$ Listing for heart transplantation, or considering long-term mechanical circulatory support as a bridge to transplantation, is the conventional approach. ${ }^{2} \mathrm{We}$ describe a patient with HLHS and failing Fontan circulation, with severe RV dilatation and severe TV regurgitation. The patient was not a candidate for heart transplantation. We have previously observed that successful restoration of atrioventricular valve competence significantly improves the outcomes in patients with univentricular circulation. ${ }^{3}$ Thus, in the patient described herein, we aimed to restore TV competency because this appeared to be his only option.

\section{CLINICAL SUMMARY}

A 6-year-old autistic boy with HLHS, aortic atresia, and mitral atresia underwent a Fontan operation with an extracardiac 18-mm GORE-TEX (W. L. Gore \& Associates, Inc, Flagstaff, Ariz) conduit and a 4-mm fenestration. A catheter study undertaken before the Fontan procedure showed RV end-diastolic pressure of $8 \mathrm{~mm} \mathrm{Hg}$. After the Fontan procedure, there was minimal TV insufficiency, normal function, and trivial neoaortic valve insufficiency. The patient was hospitalized 2 months after the Fontan procedure with severe heart failure and severe TV regurgitation. Arterial blood gas values demonstrated a $\mathrm{pH}$ of 7.18, a $\mathrm{Po}_{2}$ of $55 \mathrm{~mm} \mathrm{Hg}$, a $\mathrm{PcO}_{2}$ of $41 \mathrm{~mm} \mathrm{Hg}$, and a lactate concentration of $16.4 \mathrm{mmol} / \mathrm{L}$. The oxygen saturation was $60 \%$ to $65 \%$.
For psychosocial reasons, the patient was not a candidate for heart transplantation or long-term mechanical circulatory support. We decided to perform TV repair. The patient's condition deteriorated rapidly, and he was brought to the operating room a few hours after his admission. He had a cardiac arrest on induction of anesthesia and was resuscitated. TV annuloplasty was performed with insertion of a 30-mm Carpentier-Edwards Physio tricuspid ring (Edwards Lifesciences, Irvine, Calif) and approximation of the septal and anterior leaflets. Aortic crossclamp time was 65 minutes, and cardiopulmonary bypass time was $127 \mathrm{mi}$ nutes. The patient had complete heart block and required pacing. Intraoperative echocardiography demonstrated a moderate TV insufficiency with a central coaptation defect caused by severe ventricular dilatation (Figure 1 and Video 1). Central extracorporeal membrane oxygenation (ECMO) was electively instituted to obtain myocardial recovery.

After 5 days, however, the RV function had failed to recover. In the absence of further hemodynamic improvement and persistence of significant central TV insufficiency caused by tethering leaflets and RV dilatation, a TV replacement was undertaken with a 33-mm Perimount pericardial prosthesis (Edwards Lifesciences). Aortic crossclamp time was 75 minutes, and cardiopulmonary bypass time was 109 minutes. The patient was weaned from extracorporeal membrane oxygenation support 2 days after this operation. The next day, his chest was closed, with concomitant 


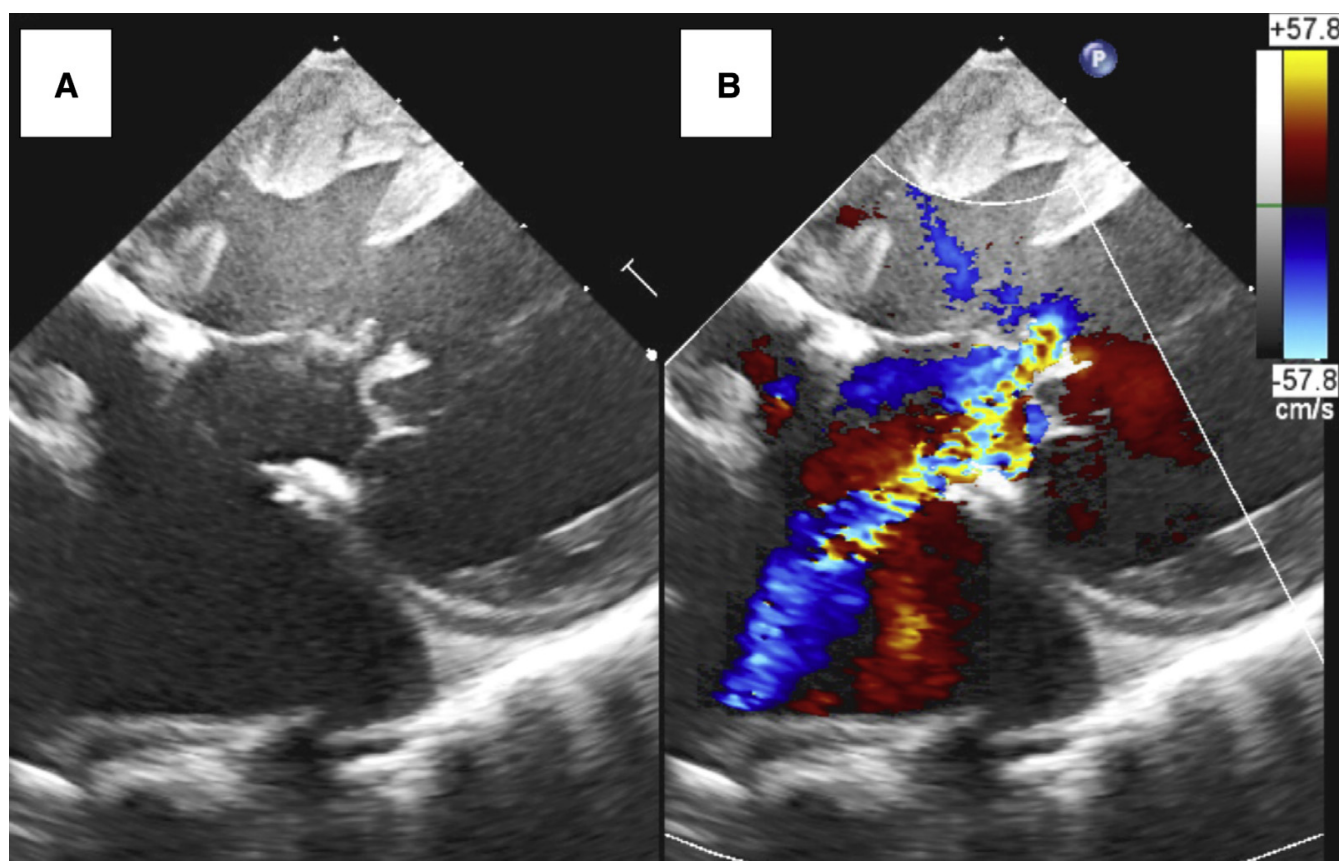

FIGURE 1. Immediate postoperative epicardial echocardiography. A, Central coaptation defect of the tricuspid valve as a result of severe right ventricular dilatation. B, Color Doppler image demonstrates persistent severe tricuspid valve insufficiency.

insertion of a permanent dual-chamber pacemaker. RV dysfunction and dilatation persisted. The patient was discharged 17 days postoperatively at home for palliative care on a regimen of aspirin, lisinopril, and diuretics. The patient was seen by his cardiologist at 2 weeks after hospital discharge, at 3 months after hospital discharge, and every 6 months thereafter. Diuretics were discontinued after 6 months. RV function started to improve 9 months after the valve replacement, and RV diameter started to reduce after 12 months. The patient recovered normal sinus rhythm after 3.5 years. At 4 years of follow-up, the RV size and function had normalized (Figure 2). At 5 years of followup, the patient was doing well, and was asymptomatic. The prosthetic valve function was normal.

\section{DISCUSSION}

In patient with HLHS and RV dilatation and failure, TV replacement is rarely performed after completion of the

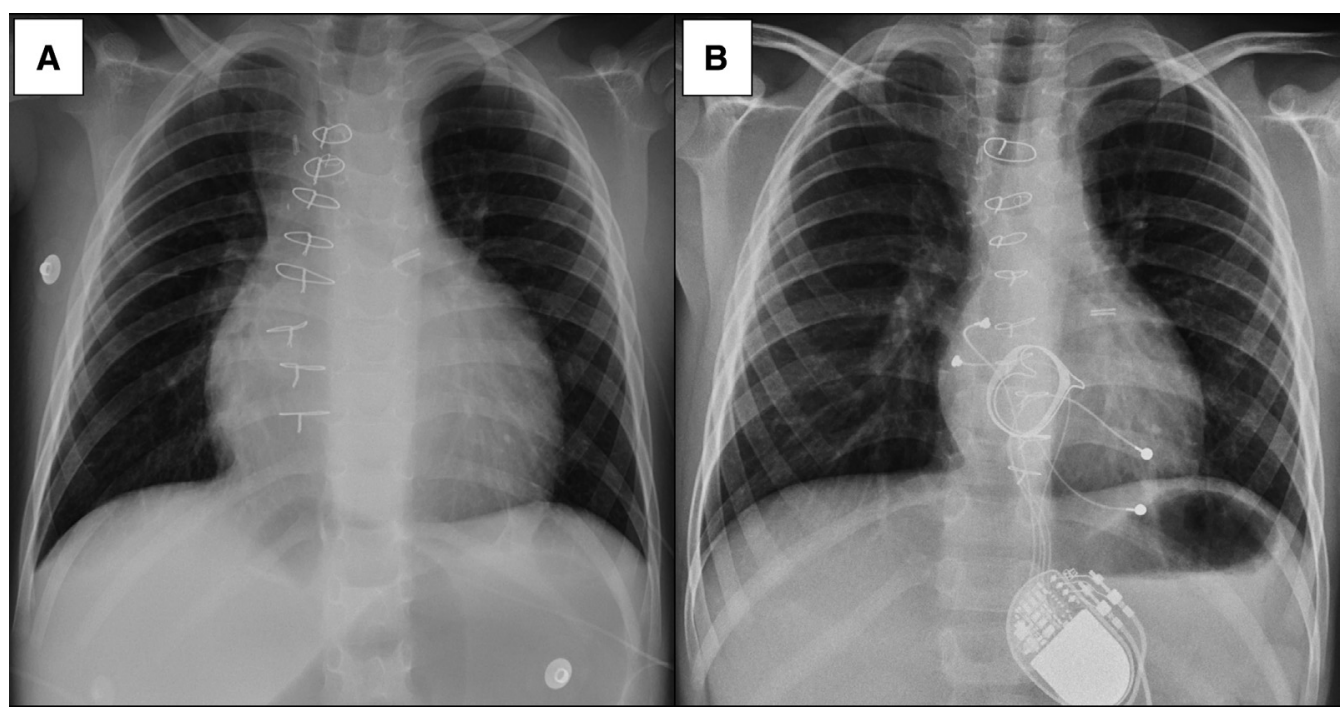

FIGURE 2. Preoperative radiograph (A) and radiograph at 4-year follow-up (B) show the reduction in the cardiothoracic ratio. 


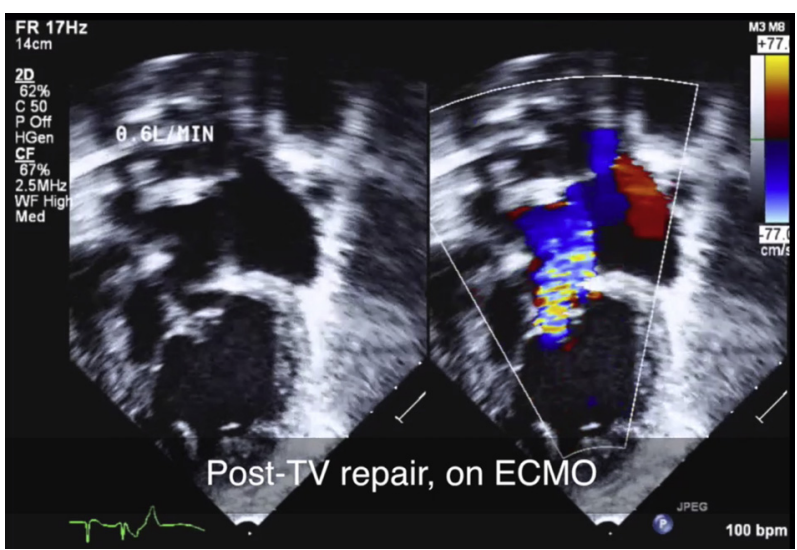

VIDEO 1. Sequential echocardiographic evolution of the right ventricular function. Video available at: https://www.jtcvs.org/article/S0022-5223(18) 30878-X/fulltext.

Fontan procefure. ${ }^{1}$ Listing for a heart transplant and considering long-term mechanical circulatory support as a bridge to transplantation are the conventional options. ${ }^{2}$ Our patient had HLHS and a failing Fontan circulation because of severe RV dilatation that resulted in severe TV regurgitation. Because of adverse psychosocial circumstances, the patient was not a candidate for transplantation. In this context of severe RV dilatation, TV repair was challenging. Severe TV insufficiency in HLHS is considered to be secondary to the failing RV, so TV repair or replacement is not commonly undertaken. In this case, our only alternative was to attempt to restore TV competence. ${ }^{3}$ The most common mechanism of TV regurgitation in patients with palliated HLHS is a prolapse of the anterior leaflet with a tethered septal leaflet and dilated annulus. ${ }^{4,5}$ Although an adequate repair technique was applied in this desperate situation, the repair was unsuccessful because of the severe RV dilatation. The residual central TV insufficiency failed to improve during postoperative extracorporeal membrane oxygenation, which was instituted in the hope of reducing RV size and recovering myocardial function. TV replacement was therefore undertaken. Severe RV dilatation and poor systolic function persisted, and the patient was discharged home for palliative care. The recovery of this patient was unexpectedly impressive.

This case illustrates that TV replacement may result in normalization of RV size and function in a patient with HLHS and failing Fontan circulation as a result of severe RV dysfunction and dilatation. As such, TV replacement may obviate the need for a transplant in a challenging subgroup of patients with failing Fontan circulation and severe dilatation of a single ventricle. Currently, this road is not taken for the suitable candidates for transplantation. Should it be?

\section{References}

1. Wong DJ, Iyengar AJ, Wheaton GR, Ramsay JM, Grigg LE, Horton S, et al Long-term outcomes after atrioventricular valve operations in patients undergoing single-ventricle palliation. Ann Thorac Surg. 2012;94:606-13; discussion 613.

2. Buratto E, Shi WY, Ye XT, Konstantinov IE. Ventricular assist devices for the failing univentricular circulation. Expert Rev Med Devices. 2017;14: 449-59.

3. Buratto E, Ye XT, Brizard CP, Brink J, d'Udekem Y, Konstantinov IE. Successful atrioventricular valve repair improves long-term outcomes in children with unbalanced atrioventricular septal defect. J Thorac Cardiovasc Surg. 2017;154: 2019-27.

4. Bautista-Hernandez V, Brown DW, Loyola H, Myers PO, Borisuk M, del Nido PJ, et al. Mechanisms of tricuspid regurgitation in patients with hypoplastic left heart syndrome undergoing tricuspid valvuloplasty. J Thorac Cardiovasc Surg. 2014; 148:832-8; discussion 838-40.

5. Mavroudis C, Stewart RD, Backer CL, Deal BJ, Young L, Franklin WH. Atrioventricular valve procedures with repeat Fontan operations: influence of valve pathology, ventricular function, and arrhythmias on outcome. Ann Thorac Surg. 2005;80: 29-36; discussion 36 . 